\title{
BMJ Open Quantitative assessment of pregnancy outcome following recurrent miscarriage clinic care: a prospective cohort study
}

\author{
Rebecca Shields (1) ,1,2 Omar Khan, ${ }^{3}$ Sarah Lim Choi Keung, ${ }^{3}$ \\ Amelia Jane Hawkes, ${ }^{1,2}$ Aisling Barry, ${ }^{4}$ Adam J Devall, ${ }^{5}$ Stephen D Quinn, ${ }^{6}$ \\ Stephen D Keay, ${ }^{7}$ Theodoros N Arvanitis (D) , ${ }^{3}$ Debra Bick (D) , ${ }^{8}$ Siobhan Quenby ${ }^{2,9}$
}

To cite: Shields R, Khan 0 , Lim Choi Keung S, et al. Quantitative assessment of pregnancy outcome following recurrent miscarriage clinic care: a prospective cohort study. BMJ Open 2022;12:e052661. doi:10.1136/ bmjopen-2021-052661

- Prepublication history and additional supplemental material for this paper are available online. To view these files, please visit the journal online (http://dx.doi.org/10.1136/ bmjopen-2021-052661).

Received 28 April 2021 Accepted 16 December 2021

Check for updates

(c) Author(s) (or their employer(s)) 2022. Re-use permitted under CC BY-NC. No commercial re-use. See rights and permissions. Published by BMJ.

For numbered affiliations see end of article.

Correspondence to Dr Rebecca Shields; rebecca.shields@uhcw.nhs.uk

\section{ABSTRACT}

Objectives To measure pregnancy outcome following attendance at a recurrent miscarriage service and identify factors that influence outcome.

Design Prospective, observational electronic cohort study. Setting Participants attending a specialist recurrent miscarriage clinic, with a history of two or more pregnancy losses. 857 new patients attended over a 30-month period and were invited to participate. Participant data were recorded on a bespoke study database, 'Tommy's Net'.

Participants 777 women consented to participate $(90.7 \%$ of new patients). 639 (82\%) women continued within the cohort, and 138 were lost to follow-up. Mean age of active participants was 34 years for women and 37 years for partners, with a mean of $3.5(1-19)$ previous pregnancy losses. Rates of obesity (maternal: $23.8 \%$, paternal: $22.4 \%$ ), smoking (maternal:7.4\%, paternal: 19.4\%) and alcohol consumption (maternal: $50 \%$, paternal: $79.2 \%$ ) were high and $55 \%$ of participants were not taking folic acid.

Outcome measures Biannual collection of pregnancy outcomes, either through prompted self-reporting, or existing hospital systems.

Results 639 (82\%) women were followed up. 404 (83.4\%) reported conception and $106(16.6 \%)$ reported no pregnancy, at least 6 months following registration. Of those that conceived, $72.8 \%$ (294/404) had a viable pregnancy. Maternal smoking and body mass index (BMI) over 30 were significantly higher in those who did not conceive $(p=0.001)$

Conclusions Tommy's Net provides a secure electronic repository on data for couples with recurrent pregnancy loss and associated outcomes. The study identified that subfertility, as well as repeated miscarriage, maternal $\mathrm{BMI}$ and smoking status, contributed to failure to achieve live birth. Study findings may enable comparison of clinic outcomes and inform the development of a personalised holistic care package.

\section{INTRODUCTION}

Miscarriage, the loss of a pregnancy prior to viability (24 weeks gestation) is common, with $15 \%$ of pregnancies ending in miscarriage. ${ }^{2}$ Most miscarriages are sporadic and occur before 12 weeks gestation. ${ }^{3}$ Recurrent miscarriage $(\mathrm{RM})$ is defined as two or three (or more) consecutive miscarriages. ${ }^{4}$ It is

\section{Strengths and limitations of this study}

- The 'Tommy's Net' e-repository and associated database contains baseline and prospective pregnancy outcome data from the largest known population of couples with recurrent miscarriage in the UK.

- Time to conception and viable pregnancy can be calculated from this data using time to event analysis.

- Obtaining follow-up data is challenging but can be improved by using a variety of data collection methods.

- Follow-up data is only requested biannually, therefore, there is an inevitable lag in data collection.

- Limited use of the English language can be a barrier for participants completing the initial lengthy questionnaire.

estimated that $1.9 \%$ of women experience two consecutive miscarriages, and approximately $0.7 \%$ suffer three or more consecutive miscarriages. ${ }^{167}$ In RM, the incidence of euploid fetal loss increases with each additional miscarriage, and the likelihood of a future successful pregnancy gradually decreases. ${ }^{8} \mathrm{RM}$ is a debilitating disorder, associated with considerable psychological morbidity. ${ }^{9}$

European and national miscarriage care guidelines recognise the importance of providing good physical care and psychological support, ${ }^{45}$ however, there are no standardised outcomes to assess care within clinics. The recent Lancet series ${ }^{1}$ on miscarriage which brought together best evidence and expert opinion, clearly outlines essential investigations for couples, dependent on their history, together with a graded model of care to optimise outcome. This could address deficiencies identified by couples in a systematic review by van den Berg et $a l,{ }^{10}$ which evaluated features of care that couples valued within miscarriage services. The review identified that explaining potential causes of 
pregnancy loss and planning for future pregnancies were specific areas couples felt could be improved .

Accurate information following attendance at an RM clinic is important for couples' counselling, stratifying care and directing research. While data does exist around outcomes in an RM setting, ${ }^{31112}$ prospective updates from clinics working under standardised guidance, ${ }^{4}$ including all couples regardless of their outcome and not only those who conceived or who participate within a research trial, is required.

The Tommy's National Centre for Miscarriage Research brings together an interdisciplinary Translational Medicine research grouping jointly at the University of Warwick, University of Birmingham and Imperial College London. The centre is dedicated to research across all aspects of miscarriage and early pregnancy complications including medical, basic scientific, social and ethical issues. A secure electronic data collection tool and e-repository (with associated database), Tommy's Net, has been developed to facilitate recording of participant data, including follow-up. ${ }^{13}$

\section{OBJECTIVES}

Our objective was to quantify the long-term cumulative live birth rate after first attendance at an RM clinic. A cohort of couples was developed, with prospective data collection of the medical and obstetric histories of both partners, investigation results and pregnancy and neonatal outcomes. The tool for collecting data on this cohort is designed to be used in multiple clinics so that success rates between clinics can be benchmarked. This objective will also allow clinics to support and assess new care pathways, identify areas needing further research, develop outcome prediction modelling and investigate new tests in future clinical trials.

\section{METHODS}

The e-repository and associated database has been developed over several years by a team with representation from University Hospital Coventry and Warwickshire (UHCW) National Health Service (NHS) Trust and University of Warwick, Imperial College and University of Birmingham. The cohort was initiated at UHCW but designed so other clinics can join. This paper summarises data collected only from couples attending UHCW RM service.

The study database complies with the regulatory requirements for Good Clinical Practice.

\section{Patient and public involvement}

An established patient and public involvement (PPI) group from within the Tommy's centre at UHCW was consulted during initial protocol development. Two further PPI sessions with 10 service users, each including 9 women and 1 partner, where consulted to ensure follow-up methods where acceptable to participants and to optimise response rates.

\section{Setting}

This cohort is from a specialist RM clinic in a tertiary referral centre (UHCW) within the UK. Miscarriage care followed European Society of Human Reproduction and Embryology (ESHRE) guidelines. ${ }^{4}$

\section{Eligibility}

All couples with a history of two or more pregnancy losses (including biochemical loss: defined as a positive pregnancy test, without ultrasound evidence of pregnancy), miscarriage, molar pregnancy, ectopic pregnancy and stillbirth) were eligible (online supplemental file 1).

\section{Recruitment}

Couples are referred to the RM clinic by their General Practitioner (family doctor). Signposting prior to referral can occur from other hospital departments (eg, early pregnancy assessment unit, acute gynaecology, fertility unit) or charities (eg, Tommy's, The Miscarriage Association). Couples are then sent information about Tommy's Net by post along with a baseline questionnaire (online supplemental file 2). At their first clinic visit a member of the research team explains Tommy's Net and asks them to consent to storage of their data.

\section{Data collection}

Both partners complete initial baseline questionnaires including demographic details, obstetric and medical history. Investigation results, blood pressure and body mass index (BMI) are recorded by clinic staff and entered into Tommy's Net (online supplemental file 2).

The Tommy's Net e-repository and database system, used for data collection and storage in the study, is based on the CURe framework, ${ }^{1314}$ a modular system for collecting research data in secondary care settings. The framework includes methods for the standardised, flexible capture and storage of data. The system is intended to link to the participating centre's clinical information systems where possible to access relevant data already collected, such as laboratory test results. Tommy's Net includes a database to organise data collected as part of the study and a web application for healthcare professionals to use for data entry, review and use in clinic (online supplemental file 3). Data in Tommy's Net can be exported for analysis. The development of Tommy's Net has seen continuous improvements based on feedback from clinicians, researchers and patients. The design of the system is intended to promote interoperability with existing hospital systems to allow researchers to use information already collected, collect pregnancy outcomes to benchmark clinics and allow researchers to identify high risk groups of patients for future research.

\section{Statistical analysis}

Statistical analysis was performed using IBM SPSS (V 27) Statistics. Time-to-event analysis was performed 
using Kaplan-Meier curves, a non-parametric method for assessing the probability of an event occurring over time. Multivariant analysis was conducted using age, BMI, cigarette smoking status, alcohol consumption and use of folic acid.

\section{Retention and pregnancy outcomes collection}

A variety of methods were assessed to collect patient reported pregnancy outcomes after the first clinic visit. Initially, women were encouraged to self-report outcomes by telephoning the clinic or completing an outcome collection form sent by email. Subsequently, automated invitations to complete this form are sent via short message service (SMS)/text message every 6 months requesting information for follow-up. This invitation consists of a single use link allowing the research team to trace the responses back to the patient identifiable baseline information.

Further outcome data are collected through viability scan visits, which can be accessed following initial review in the RM service and using existing hospital systems. Researchers used a maternity database, Evolution, and a local intranet service to improve follow-up and to validate participant reported information.

Using a variety of methods to collect outcomes improves follow-up rate, however, this does require researcher vigilance to avoid duplicate data entry. $17.8 \%$ of participants are still lost to follow-up, therefore, more work is needed in this area to encourage continuous engagement of participants (figure 1).

\section{Improving baseline data}

In the first 3 months of recruitment, a number of couples $(n=83)$ consented to the study but did not complete the baseline questionnaire. This resulted in their data being marked as 'inactive' within the database (ie, consented to the cohort study but not returned initial baseline questionnaires). On receipt of the baseline questionnaires, participants are 'activated' and followed up 6 monthly ( $\mathrm{n}=10 / 83$ to date). Our process has been updated so critical data items are collected by the clinician from all couples who consent before leaving the initial clinic appointment. Participants are no longer registered within the database until they have completed the initial baseline questionnaire.

\section{Improving pregnancy outcome data collection}

Initial pregnancy outcome data collection was poor with only $25 \%$ reporting their outcome, mainly due to technical difficulties in completing electronic versions of the forms for the participants. The response rate has gradually improved with development of a text message system. This was followed by other improvements such as a series of changes to the text message wording, by including partners in the messages, and changing the timing of the texts (with the majority sent in the afternoon or evening). Reminder messages are sent after 48 hours and 1 week (if no responses from the initial text are received). Changes

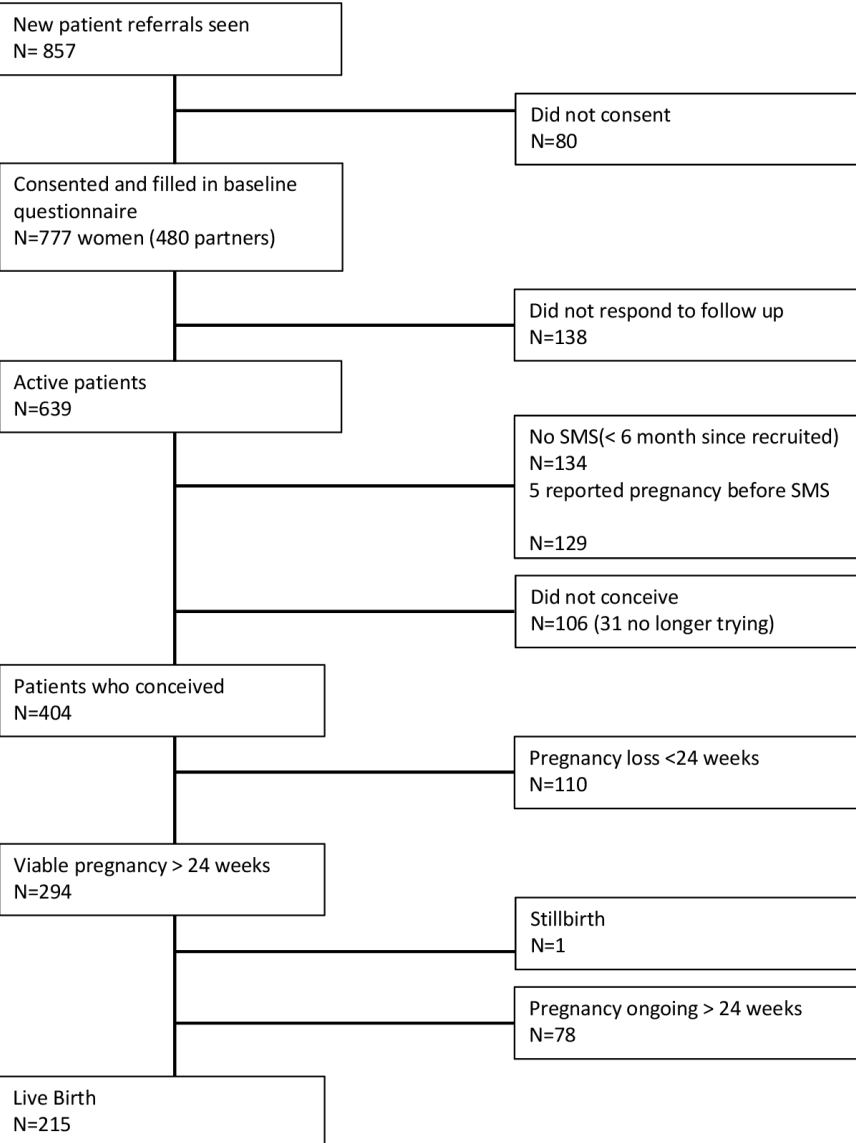

Figure 1 Flow diagram of cohort.

have been informed by PPI groups, which were used to understand further why participants fail to respond to follow-up SMS text message. Some explained that once they had had a baby they were busy - and forgot to reply. Conversely, repeated reporting of no pregnancy, or miscarriage was felt to be disheartening, or less important. We hope through education and careful wording of the questionnaire the response rate will continue to improve.

These approaches have contributed to an increase in response rate and combined with data from existing hospital systems, the response rate for pregnancy outcomes was $82.2 \%$.

Data linkage with a general practice database was not deemed useful, because few miscarriages are recorded on the local general practice databases. Furthermore, there was a lack of standardisation in pregnancy data in primary care, though automated links with both primary and secondary care electronic health systems are still planned. The maternity services database may provide a fruitful source of pregnancy outcome data in the future.

\section{RESULTS}

\section{Analysis of cumulative live birth rate}

Between May 2017 and January 2020, 777 women (and 480 partners) who attended the RM clinic completed a baseline questionnaire and consented for their data to be included in the database (figure 1). One hundred and 
Table 1 Comparison of demographics for all active participants, participants that did not conceive and those that were lost to follow-up

\begin{tabular}{|c|c|c|c|}
\hline & $\begin{array}{l}\text { Total no active patients continuing in } \\
\text { cohort }\end{array}$ & $\begin{array}{l}\text { Those that did not conceive } \\
\text { within the continuing cohort }\end{array}$ & $P$ value \\
\hline No & 639 & 106 & \\
\hline \multirow[t]{4}{*}{ Ethnicity } & White: $84 \%(436 / 519)$ & White $85.5 \%(65 / 76)$ & \\
\hline & Mixed: $2.1 \%(11)$ & Mixed: $2.6 \%(2)$ & \\
\hline & Other: $1.7 \%(9)$ & Other: $1.3 \%(1)$ & \\
\hline & Unknown (120) & Unknown (30) & \\
\hline Average no of previous live birth & 0.6 & 0.15 & 0.36 \\
\hline $\begin{array}{l}\text { Average no of previous } \\
\text { miscarriages }\end{array}$ & 3.5 & 3.6 & \\
\hline Alcohol $\mathrm{Y} / \mathrm{N}$ & Yes: 278 (50\%) & Yes: 51 (58\%) & 0.083 \\
\hline Units & $5.54(0.5-30)$ & $5.03(0.5-35)$ & $<0.001$ \\
\hline Folic acid & Yes: 292 (45.5\%) & Yes: 35 (47.17\%) & $<0.001$ \\
\hline
\end{tabular}

BMI, body mass index.

thirty-eight $(17.8 \%)$ participants were lost to follow-up (no response to SMS, or information obtained for hospital databases), therefore 639 women are active within Tommy's Net. One hundred and thirty-four of these women are within 6 months of consenting to the study and have not yet received a scheduled SMS. Five of these women have reported conceiving out with the SMS system with the data captured through early pregnancy scan clinics. Of the active women, their mean age was 34 years (table 1) and mean number of previous pregnancy losses was 3.5 (range 1-19). Demographic characteristics including age, ethnicity, alcohol intake, folic acid use and previous live births were not statistically different between participants who conceived and those who did not (table 1 ). Statistically more participants who did not conceive smoked and had a BMI over 30 .

\section{Pregnancy results}

Four hundred and four of these women reported conceiving. One hundred and six (16.6\%) women reported no pregnancy at least 6 months following registration, 31 (4\%) of whom are no longer trying to conceive. Of those that conceived $72.8 \%$ (294/404) had a viable pregnancy (215 live births, 1 stillbirth, remainder currently $>24$ weeks at time of initial analysis). Analysis of data exported from the database in January 2020, revealed a conception of rate of $81 \%$ after 2 years within the cohort and viable pregnancy rate (pregnancy over 24 weeks or live birth at time of export) of $60 \% 2$ years after attending the RM clinic (figure 2). Age does impact on time to conception and time to viable pregnancy, with women of 25-34 years being more likely to have a viable pregnancy 2 years after initial review than other age groups (figure 3). Partner age within this cohort did not have a marked effect on time to conception or viable pregnancy, particularly within the first year after initial consultation.

After 1 year in the cohort, there is a $30 \%$ difference between the number of couples who conceive and those who reach viable pregnancy. This difference/gap gradually decreases and plateaus after 900 days to a difference of $19 \%$ (conception rate $82 \%$ with $63 \%$ reaching over 24 weeks gestation). The couples within this 'gap' represent those within our clinic who conceive but miscarry prior to viability despite current intervention and support. This

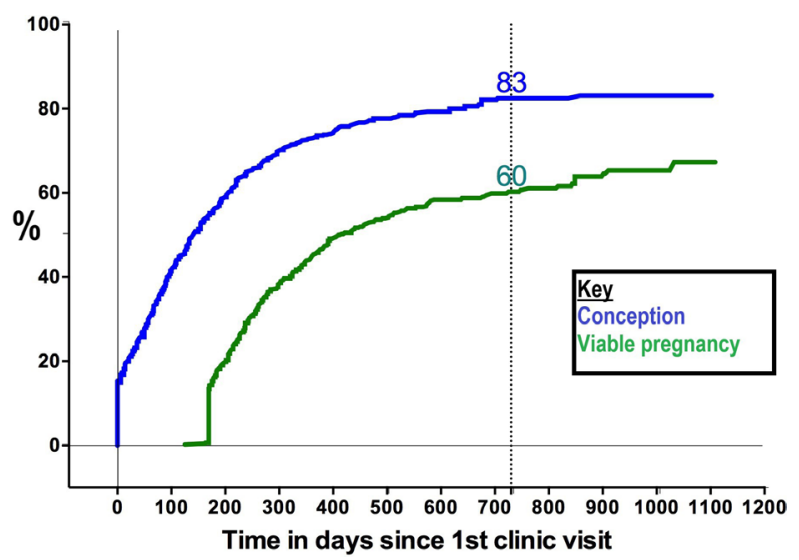

Figure 2 Cumulative rate over time, from initial consultation to conception and viable pregnancy (>24 weeks gestation). 

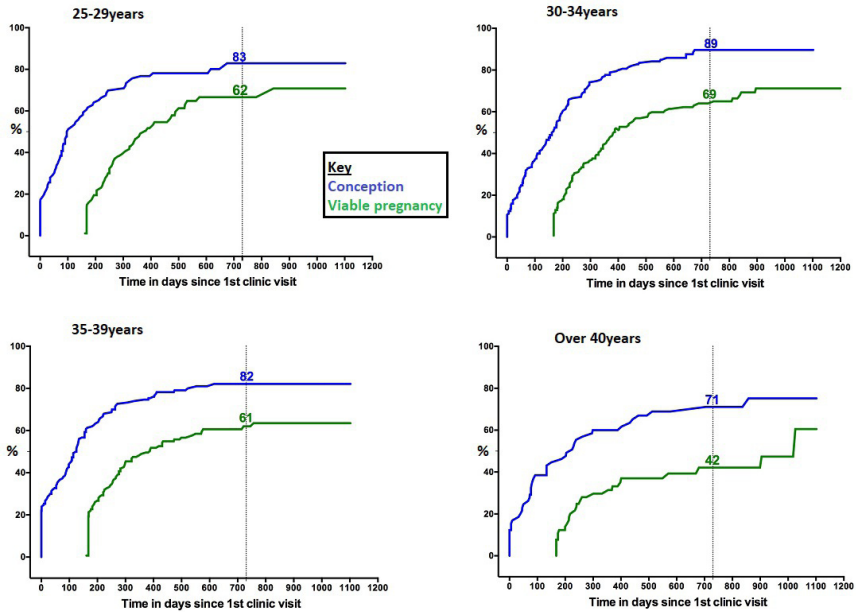

Figure 3 Comparing conception to $>24$ weeks gestation by age.

gap is maintained within the 30-39 years age group but is less pronounced within those who conceive aged 25-29 years (figure 3). Female BMI over 30 and female smoking status along with miscarriage history increases the time from initial consultation to conception and viable pregnancy within this patient group (figures 4-6). Partner BMI, smoking status or alcohol intake did not impact on time to conception or time to viable pregnancy.

A healthy BMI increases the chance of viable pregnancy, particularly when compared with a maternal BMI over $30 \mathrm{~kg} / \mathrm{m} 2$ (figure 4). Having a BMI over 30 increases the time taken to viable pregnancy by 100-200 days. Within this population BMI does not appear to significantly change the time to conception (figure 7), particularly within the first 300 days.

Couples who have had four or more miscarriages take longer to conceive, compared with couples who have has three or less miscarriages (figure 5). There is a $17 \%$ gap within couples who have had four or more losses when comparing the rate of conception with viable pregnancy.
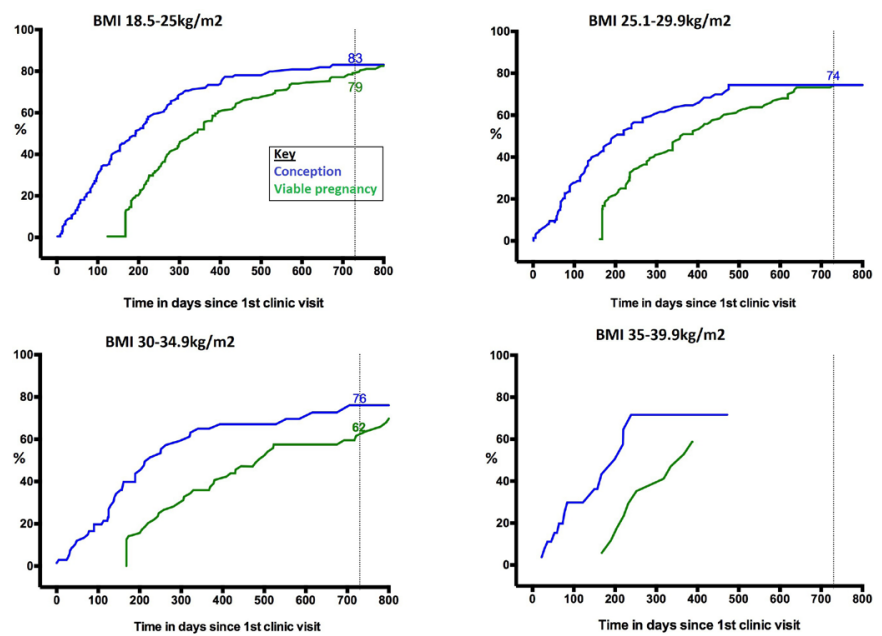

Figure 4 Time from initial consultation to conception/>24 weeks gestation by female BMI range. BMI, body mass index.
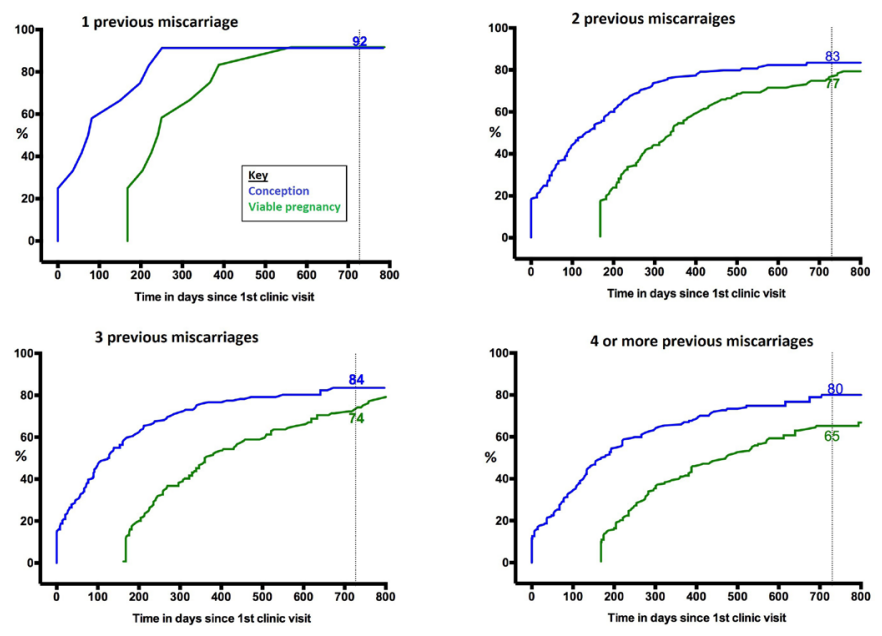

Figure 5 Time from initial consultation to conception/>24 weeks gestation by miscarriage history.

This gap represents those that continue to miscarry and should be a population where research should be focused.

Smoking status impacts on time to conception (figure 6). Females that smoke take longer to conceive with significantly more never conceiving.

\section{DISCUSSION}

\section{Database}

We have developed an electronic method of obtaining outcomes from women following attendance at an RM clinic. These outcomes can be used to assess RM care and form a 'benchmark' to compare clinical services and interventions. The electronic cohort provides clinic outcome data in real time (online supplemental file 3), and can be used for counselling couples as to both the chance of their next pregnancy succeeding and their cumulative time to live birth. This is novel, as data ${ }^{3} 1112$ identified at literature review could not be generalised to the UK population. Lund $e t a l^{11}$ used a national, Danish registry to collect live birth data from attendees up to 5 years after their visit to an RM clinic. Registry data were collected retrospectively and lacks information from couples who moved to other countries. Brigham et $a \hat{l}^{3}$

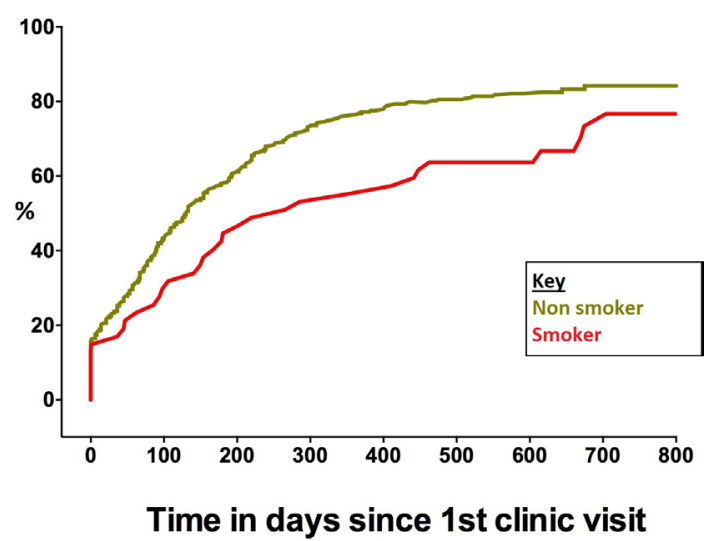

Figure 6 Time from initial consultation to conception by female smoking status. 


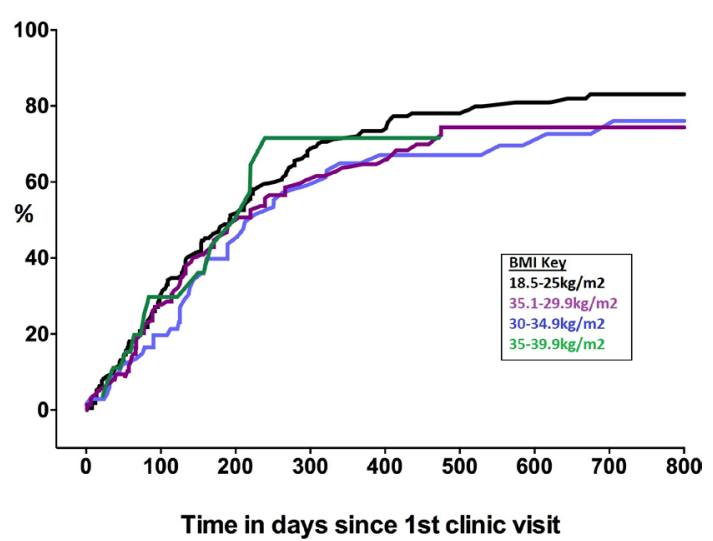

Figure 7 Time from initial consultation to conception by BMI. BMI, body mass index.

analysed 716 couples over a 10-year period in their Liverpool clinic, with pregnancy outcome data on 325 patients with unexplained RM. Data were only reported on those who conceived and had their pregnancy and birth care at the same hospital. These datasets are now over 20 years old. Kling $e t a l^{12}$ published more recent data based on a tertiary referral immunological centre within Germany. Seven hundred and nineteen couples were followed up for a median of 33.7 months, producing time to pregnancy and time to delivery over a 5-year period. While this is valuable data the study excluded couples who already had children within the partnership (25\% within our clinic) and used immunotherapy in a proportion of couples which is not routinely used within the UK. It also asked for patient reported outcomes between 9 months to 4 years after the event which could be prone to recall bias. This database will continue to collect and provide prospective outcomes of all those who attend this RM clinic and, as use increases within the other sites it will allow comparison of outcomes with the aim of sharing good practice to improve patient care.

\section{Infertility}

The time to conception curve within our RM population is similar to that in the general population. ${ }^{15}{ }^{16}$ It is often assumed that the reason couples do not have a baby after attendance at RM services is because they have miscarried again. This however is only part of the picture. Analysis to date has identified that within our cohort $16.6 \%(n=106)$ of couples fail to conceive within the follow-up period. These patients are similar ethnicity when compared with all within the active cohort. They do have a trend to a higher BMI and are statistically more likely to smoke. Whist the mean age was similar in those conceived and those who did not, the expected effect of age on conception was demonstrated with a lower conception rate after 2 years in those over 40 years old.

Reasons why couples do not conceive are complex. Couples were encouraged to conceive immediately from first consultation, while investigation results are awaited. Anecdotal evidence from the text message system and PPI groups shows some couples feel unable to continue trying to conceive due to the potential risk of repeat miscarriage. Recent research ${ }^{17}$ has highlighted an increased risk of post-traumatic stress disorder following pregnancy loss. We hypothesise that the psychological impact of miscarriage may stop couples from trying to conceive again. This is an important area on which to focus research and facilitate additional counselling and support.

Other couples may be unable to conceive despite actively trying. Identifying this subgroup of couples earlier could facilitate prompt referral to fertility services for assessment and treatment. Potentially increasing their chance of conception and ultimately live birth. Within this population, the rate of conception decreases significantly 1 year after initial consultation (figure 2). Sixtyfive per cent of couples conceive within 1 year of initial consultation, with only an additional 15\% conceiving in the second year. In view of this decrease in pace of conception we suggest referral to fertility services should be considered within this population after 1 year.

Throughout the UK, access to NHS-funded fertility treatment is dependent on maternal weight, smoking status, as well as age and parity. Addressing these factors early in the couple's fertility journey may help to manage expectations prior to referral and reduce any delay in starting treatment. We recognise that weight particularly can be a sensitive issue and difficult to manage. Open and honest discussion, without blame, along with support and advice that, for example, joining group programmes for exercise and dietary modification can lead to more pregnancies than weight loss alone ${ }^{17}$ should be given. Referral to specialised weight management services including bariatric dietetic and surgical teams could be discussed if appropriate.

There may be a role for ovarian reserve assessment for women who have previously taken over 12 months to conceive. Having strong links, or an integrated multidisciplinary preconception service including miscarriage and fertility specialists along with psychologist and counsellors may allow a more cohesive approach to these couples and increase their chance of having a viable pregnancy as well as providing continuity of medical and psychological care.

\section{Outcome data}

Comparing the 'time to conception' and 'time to viable pregnancy' curves illustrate the importance of assessing cumulative data. There is by definition a lag between conception and reaching 24 weeks pregnant, but following this the difference between the curves represents delay in live birth due to miscarriage. This gap decreases initially and may represent an impact from interventions and support within the RM service. The importance of support to couples will be studied further during a planned qualitative study using semi-structured interviews of affected couples. After 900 days the gap between the curves is static and represents those whom despite conceiving have not yet had a child. This is a 
group which resources and research should be targeted to further understand reasons for miscarriage.

\section{Health education}

It is well documented that miscarriage risk increases with BMI over $30 \mathrm{~kg} / \mathrm{m}^{2}$ and smoking status. ${ }^{16-21}$ Despite this $23.8 \%$ of women within the cohort have a BMI over $30 \mathrm{~kg} / \mathrm{m}^{2}$ and $7.4 \%$ smoke tobacco. Modifying these lifestyle factors through preconception counselling may reduce the chance of miscarriage and improve pregnancy outcome by reducing the incidence of, for example, gestational diabetes. Future research could be targeted at support in weight loss and smoking cessation.

\section{Limitations and strengths}

The Tommy's Net e-repository and associated database contains baseline and prospective pregnancy outcome data from the largest known population of couples with RM in the UK. It allows calculation of 'time to conception' and 'time to viable pregnancy' using time to event analysis. This large dataset aims to facilitate future studies within an RM population.

Obtaining follow-up data is challenging. Using a variety of methods including self-reporting through the text message link and local hospital systems has improved our follow-up rate.

Couples with limited English were unlikely to complete the lengthy questionnaire, which is currently only available in English. This means that this study is likely to miss high risk groups within our community

The introduction of the maternity services database could provide a valuable resource to enable improved follow-up. Couples attend this RM clinic from all over the UK. Currently couples who deliver within our trust have at least two ways in which we can capture their outcome (short message service (SMS) text message and hospital database with or without scan clinic information). These checks are not available to couples who have travelled some distance to attend and therefore may be underrepresented within the active participants group.

SMS text message requests for follow-up are only sent every 6 months. This means that for the first 6 months that participants are within the study we do not expect to collect any outcome data. Some of these participants may go on to become 'inactive' and be removed from analysis.

\section{CONCLUSION}

We have developed a user-friendly electronic database, storing comprehensive data, which can provide accurate time to conception and data on viable pregnancies to facilitate analysis into factors contributing to RM. $16.6 \%$ of women within our clinic did not conceive and early referral to fertility services should be facilitated. Over $20 \%$ of women within the cohort have a BMI of over $30 \%$ and $7.4 \%$ smoke. Preconception counselling should be targeted at weight and smoking status with an aim of reducing miscarriage.

\section{Author affiliations}

${ }^{1}$ Division of Reproductive Health, University of Warwick, Coventry, UK

${ }^{2}$ Tommy's National Centre for Miscarriage Research, University Hospitals Coventry and Warwickshire NHS Trust, Coventry, UK

${ }^{3}$ Institute of Digital Healthcare, University of Warwick, Coventry, UK

${ }^{4}$ Warwick Medical School, University of Warwick, Coventry, UK

${ }^{5}$ Tommy's National Centre for Miscarriage Research, Institute of Metabolism and Systems Research, University of Birmingham, Birmingham, UK

${ }^{6}$. Tommy's National Centre for Miscarriage Research, Institute of Metabolism and Systems Research, Imperial College London, London, UK

${ }^{7}$ Centre for Reproductive Medicine, University Hospitals Coventry and Warwickshire NHS Trust, Coventry, UK

${ }^{8}$ Warwick Clinical Trials Unit, Warwick Medical School, University of Warwick, Coventry, UK

${ }^{9}$ Institute of Early Life, University of Warwick, Coventry, UK

\section{Twitter Theodoros N Arvanitis @TheoArvanitis and Debra Bick @debrabick}

Acknowledgements Thank you to all our participants, everyone in the Tommy's Team at the Biomedical Research Unit, UHCW and Tommy's for funding Tommy's Net. Thank you also to all who participated in our PPI groups.

Contributors SDQ had the initial concept. OK, SLCK and TNA designed and developed Tommy's net database and extracted initial data. RS analysed the data and interpreted it along with SDQ. RS wrote the initial draft, which was revised by SDQ and DB, and reviewed by AJH, OK, SLCK, TNA, AB, AJD, SDQ and SDK. All commented on initial drafts and approved the final version. RS is the guarantor for the article.

Funding Tommy's Baby Charity (award number N/A).

Competing interests None declared.

Patient consent for publication Not applicable.

Ethics approval This study was approved by West Midlands-South Birmingham Regional Ethics Committee IRAS No: 213740, 2225751 REC Ref: 17/WM/0050: 17/ WM/208.

Provenance and peer review Not commissioned; externally peer reviewed.

Data availability statement Data are available on reasonable request. Original data may be available on reasonable request (under ethics restrictions) by emailing the corresponding author.

Supplemental material This content has been supplied by the author(s). It has not been vetted by BMJ Publishing Group Limited (BMJ) and may not have been peer-reviewed. Any opinions or recommendations discussed are solely those of the author(s) and are not endorsed by BMJ. BMJ disclaims all liability and responsibility arising from any reliance placed on the content. Where the content includes any translated material, BMJ does not warrant the accuracy and reliability of the translations (including but not limited to local regulations, clinical guidelines, terminology, drug names and drug dosages), and is not responsible for any error and/or omissions arising from translation and adaptation or otherwise.

Open access This is an open access article distributed in accordance with the Creative Commons Attribution Non Commercial (CC BY-NC 4.0) license, which permits others to distribute, remix, adapt, build upon this work non-commercially, and license their derivative works on different terms, provided the original work is properly cited, appropriate credit is given, any changes made indicated, and the use is non-commercial. See: http://creativecommons.org/licenses/by-nc/4.0/.

\section{ORCID iDs}

Rebecca Shields http://orcid.org/0000-0002-7442-5242

Theodoros N Arvanitis http://orcid.org/0000-0001-5473-135X

Debra Bick http://orcid.org/0000-0002-8557-7276

\section{REFERENCES}

1 Quenby S, Gallos ID, Dhillon-Smith RK, et al. Miscarriage matters: the epidemiological, physical, psychological, and economic costs of early pregnancy loss. Lancet 2021;397:1658-67.

2 Stephenson M, Kutteh W. Evaluation and management of recurrent early pregnancy loss. Clin Obstet Gynecol 2007;50:132-45.

3 Brigham SA, Conlon C, Farquharson RG. A longitudinal study of pregnancy outcome following idiopathic recurrent miscarriage. Hum Reprod 1999;14:2868-71. 
4 ESHRE Early Pregnancy Guideline Development Group (GDG). Recurrent pregnancy loss, European Society of reproduction and embryology, 2017.

5 Regan L, Backos M, Rai R. Recurrent miscarriage, investigations and treatment of couples. Royal College of Obstetricians and Gynaecologists, Greentop Guideline, 2011.

6 Practice Committee of the American Society for Reproductive Medicine. Evaluation and treatment of recurrent pregnancy loss: a Committee opinion. Fertil Steril 2012;98:1103-11.

7 Rai R, Regan L. Recurrent miscarriage. Lancet 2006;368:601-11.

8 Ogasawara M, Aoki K, Okada S, et al. Embryonic karyotype of abortuses in relation to the number of previous miscarriages. Fertil Steril 2000;73:300-4.

9 Chen S-L, Chang S-M, Kuo P-L, et al. Stress, anxiety and depression perceived by couples with recurrent miscarriage. Int J Nurs Pract 2020;26:e12796.

10 van den Berg MMJ, Dancet EAF, Erlikh T, et al. Patient-Centered early pregnancy care: a systematic review of quantitative and qualitative studies on the perspectives of women and their partners. Hum Reprod Update 2018;24:106-18.

11 Lund M, Kamper-Jørgensen M, Nielsen HS, et al. Prognosis for live birth in women with recurrent miscarriage: what is the best measure of success? Obstet Gynecol 2012;119:37-43.

12 Kling C, Hedderich J, Kabelitz D. Fertility after recurrent miscarriages: results of an observational cohort study. Arch Gynecol Obstet 2018;297:205-19.
13 Khan O, LimChoiKeung SN, Quenby S. Design considerations for tools supporting multi-centre clinical trials. AMIA 2018 Summit on Clinical Research Informatics, San Francisco, CA: USA, 2018:520.

14 Ogunsina I, Lim Choi Keung SN, Rossiter J. An extensible model for multi-specialty patient record systems in clinical research. Proceedings of the 10th International Conference on Information Communication Technologies in Health, Samos: Greece, 2012. p.:190-200.

15 Sozou PD, Hartshorne GM. Time to pregnancy: a computational method for using the duration of non-conception for predicting conception. PLoS One 2012;7:e46544.

16 Farren J, Jalmbrant M, Falconieri N, et al. Posttraumatic stress, anxiety and depression following miscarriage and ectopic pregnancy: a multicenter, prospective, cohort study. Am J Obstet Gynecol 2020;222:367.e1-367.e22

17 Fertility problems: assessment and treatment CG156.

18 Mishra GD, Dobson AJ, Schofield MJ. Cigarette smoking, menstrual symptoms and miscarriage among young women. Aust N Z J Public Health 2000;24:413-20.

19 Kmietowicz Z. Smoking is causing impotence, miscarriages, and infertility. BMJ 2004;328:364.2.

20 Pineles BL, Park E, Samet JM. Systematic review and meta-analysis of miscarriage and maternal exposure to tobacco smoke during pregnancy. Am J Epidemiol 2014;179:807-23.

21 Matjila MJ, Hoffman A, van der Spuy ZM. Medical conditions associated with recurrent miscarriage-ls BMI the tip of the iceberg? Eur J Obstet Gynecol Reprod Biol 2017;214:91-6. 